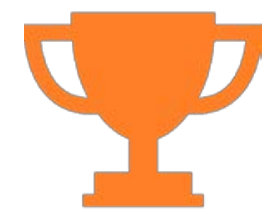

\title{
DiOTTOS
}

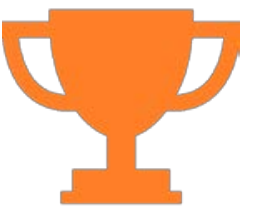

\section{Estudio sobre el uso de la evidencia científica como argumento en los relatos periodísticos sobre terapias complementarias en los principales diarios digitales ${ }^{1}$ \\ Study on the use of scientific evidence as an argument in journalistic stories about complementary therapies in the main digital newspapers}

Recibido: 2018-09-13

Sara Moreno Tarín

Universitat de València

Aceptado: 2018-12-11

\section{Resumen}

El conjunto de técnicas relacionadas con la salud que se engloban bajo el concepto de medicina tradicional y complementaria (MTC) son cada vez más demandadas y utilizadas en todo el mundo. En España, prácticamente la totalidad de la población conoce alguna de estas terapias y casi un cuarto de la población las ha utilizado alguna vez como tratamiento médico.

Consecuentemente, este fenómeno suscita un interés por parte de la comunidad sanitaria y científica y es un tema cada día más recurrente en la agenda mediática española. El presente estudio analiza el peso de "la evidencia científica" como argumento en el debate sobre las terapias

\begin{abstract}
The set of techniques related to health which fall within the concept of traditional and complementary medicine (TCM) are increasingly demanded and used throughout the world. In Spain, practically the entire population knows some of these therapies and almost a quarter of the population has used them as a medical treatment.
\end{abstract}

Consequently, this phenomenon arouses interest among the medical and scientific communities and is becoming an increasingly recurring topic on the Spanish media agenda. This study analyzes the weight of 'scientific evidence' as an argument on the debate about unconventional therapies through the

\footnotetext{
${ }^{1} 1 \mathrm{El}$ presente trabajo ha sido desarrollado en el marco del proyecto de investigación «Estudio y clasificación de las terapias naturales, complementarias y alternativas a través de los medios de comunicación y de las redes sociales. Ideas y valores de transferencia al imaginario social» (CSO201457778-R), financiado por el Ministerio de Economía y Competitividad y por fondos FEDER de la Unión Europea.
} 
Moreno Tarín, S. (2019).

Estudio sobre el uso de la evidencia científica como argumento en los relatos periodísticos sobre terapias complementarias en los principales diarios digitales

pp. 122/152

no convencionales a través de los flujos de información que se difunden en los diarios digitales de mayor audiencia en España durante el trienio 2015, 2016 y 2017. El análisis se realiza a dos tipos de noticias cuya temática principal está relacionada con la homeopatía, la acupuntura, la reflexología o el quiromasaje; por una parte, las noticias con una posición favorable $\mathrm{y}$, por otra, aquellas cuya perspectiva es escéptica, todas ellas publicadas en los siguientes diarios digitales: El Periódico, El País, El Mundo, La Vanguardia y $A B C$. Los resultados muestran una infrarrepresentación significativa de la eficacia científicamente probada de las MTC, como relato periodístico, ofreciendo al público una argumentación incompleta y confusa al respecto.

\section{Palabras clave}

Medicina complementaria, evidencia científica, noticia científica, periodismo científico, periodismo digital flows of information which are disseminated in the digital newspapers with the highest audience in Spain in the three years 2015-2017. The analysis focuses on two types of stories whose main subject is related to homeopathy, acupuncture, reflexology or chiromassage. On the one hand, is studied the science stories which adopts a favorable stance and, on the other hand, the science news with a skeptic perspective on the matter, all of them published in the following digital dailies: El Periódico, El País, El Mundo, La Vanguardia, and ABC. The results show a significant underrepresentation of the scientifically proven efficacy of the TCM, as journalistic writing, offering the public incomplete and confusing arguments in this regard.

Key words

Complementary medicine, scientific evidence, science news, science journalism, digital journalism

\section{Introducción}

Según la Organización Mundial de la Salud (OMS) en su documento relativo a la estrategia sobre medicina tradicional 2014-2023, la "medicina tradicional es la suma total de los conocimientos, capacidades y prácticas basados en las teorías, creencias y experiencias propias de diferentes culturas, bien sean explicables o no, utilizadas para mantener la salud y prevenir, diagnosticar, mejorar o tratar enfermedades físicas y mentales". Por otro lado, los términos "medicina complementaria” o "medicina alternativa" aluden a "un amplio conjunto de prácticas de atención a la salud que no forman parte de la tradición ni de la medicina convencional de un país, dado que no están totalmente integradas en el sistema de salud predominante". ${ }^{2} \mathrm{Y}$ por último, la "medicina tradicional y complementaria (MTC)" fusiona los términos "medicina

\footnotetext{
${ }^{2}$ En algunos países se utilizan estos dos términos indistintamente para hacer referencia a la medicina tradicional.
} 
Moreno Tarín, S. (2019).

Estudio sobre el uso de la evidencia científica como argumento en los relatos periodísticos sobre terapias complementarias en los principales diarios digitales

pp. 122/152

tradicional” y “medicina complementaria”, y plantea una visión no reduccionista que abarca productos, prácticas y profesionales.

La MTC es un concepto con el que el sistema sanitario está familiarizado en la mayoría de países. Este tipo de medicina se practica en casi todo el mundo y, además, su demanda va en aumento (Ballvé Moreno, 2003; Ministerio de Sanidad, 2011; OMS, 2013). Según el primer análisis de la situación de las terapias naturales del Ministerio de Sanidad, Política Social e Igualdad, realizado en 2011, en países en vías de desarrollo, como es el caso de los pertenecientes a África donde un $80 \%$ de la población las utiliza, estas se encuentran muy extendidas. En China también están muy instauradas, representando un $40 \%$ de la asistencia sanitaria ya que están muy enraizadas en el sistema credencial de la cultura oriental. En algunos países europeos, asiáticos y del subcontinente norteamericano, a pesar de que estas terapias no están reconocidas por las autoridades sanitarias de forma general, se llevan a cabo de forma habitual en prácticamente todos los países. De hecho, se ha llegado a desarrollar en algunos países determinada regulación en relación a los centros en los que se realizan y a la formación de los profesionales que las llevan a cabo (Ministerio de Sanidad, 2011).

El aumento en la demanda y la utilización de este tipo de terapias en los últimos años conlleva un incremento de la atención, por parte de legisladores, en relación tanto a la seguridad que éstas pueden ofrecer como a la eficacia y evidencia científica en las que dichas técnicas se basan. En la puesta en marcha de una política de integración de este tipo de terapias, en el sistema de atención a la salud de los distintos países, es necesario no sólo realizar una contextualización cultural de la MTC en cada país, sino también ejecutar una política basada en el conocimiento (OMS, 2013). Es por este motivo que la OMS a la hora de establecer una estrategia para integrar la medicina tradicional y complementaria en el sistema de salud, adopta la intención de “alentar la investigación estratégica en materia de MTC”, y para ello pretende "respaldar proyectos de investigación clínica sobre su seguridad y eficacia y abogar por el uso racional de la MTC mediante el fomento de su utilización basada en pruebas científicas”.

Centrándonos en el caso de la Unión Europea, según el Ministerio de Sanidad (2011), las terapias más utilizadas son la acupuntura, homeopatía, fitoterapia, medicina antroposófica, naturopatía, medicina tradicional china, osteopatía y quiropráctica. A pesar de que más de 100 millones de europeos y europeas utilizan las MTC y de estos una quinta parte recurre a ellas con regularidad (OMS, 2013), no existe una normativa europea que regule la MTC de forma homogénea, debido a los distintos enfoques de los países en relación al uso de las misma.

Encontramos dos corrientes marcadas sobre la autorización de los profesionales que deben llevar a cabo la MTC en Europa. ${ }^{3}$ Por un lado aquella representada en gran

\footnotetext{
${ }^{3}$ Pueden encontrarse de forma más detallada las normativas de los países europeos que poseen regulación sobre las MTC en el documento de análisis de la situación de las terapias naturales del Ministerio de Sanidad (2011).
} 
Moreno Tarín, S. (2019).

Estudio sobre el uso de la evidencia científica como argumento en los relatos periodísticos sobre terapias complementarias en los principales diarios digitales

pp. 122/152

parte por los países nórdicos, los cuales consideran que cualquier persona puede llevar a cabo los cuidados sanitarios de la MTC, excepto determinadas acciones exclusivamente autorizadas para personal médico. Por otro lado, y en dirección opuesta está la visión de países como Francia, Bélgica o Luxemburgo, los cuales reservan la autorización de estas prácticas únicamente al ámbito médico. De esta falta de armonización, junto con las diferentes reglamentaciones de las prácticas y productos, deriva una situación especialmente compleja para la regulación europea del contexto de la atención sanitaria transfronteriza.

La OMS (2013) insta a los Estados Miembros a "comprender el carácter específico de su sector nacional y establecer datos de referencia válidos y generales para su ulterior desarrollo" para así "adoptar una decisión con conocimiento de causa sobre la manera en que se supervisará la MTC en sus jurisdicciones”. Para ello, deberán llevarse a cabo varias estrategias, según esta organización internacional. Una de ellas es fomentar actividades de investigación científica y de gestión del conocimiento para desarrollar un fundamento epistemológico en relación a las MTC que agilice la gestión activa a través de políticas nacionales e internacionales. Así, controlar la seguridad y eficacia en la realización de la MTC y ser integradas en el modelo sanitario de cada país. Otra de las estrategias propuestas por la OMS (2013) está dirigida a "Identificar los medios por los que la información relativa a la MTC se transmite a través de los profesionales, la publicidad de productos, las prácticas y los medios de comunicación”.

\subsection{Medicina Tradicional y Complementaria en España}

En 2008 el Observatorio de Terapias Naturales (OTN) desarrolló el último estudio específico sobre uso y hábitos de consumo de algunas terapias de la MTC en España. ${ }^{4}$ Según este trabajo el 95,4\% de la población española conoce alguna terapia de la MTC y el 23,6\% las ha utilizado alguna vez, datos que concuerdan con los resultados del último barómetro del CIS (febrero 2018), siendo el yoga, la acupuntura, el masaje terapéutico y la meditación las más conocidas,

respectivamente. El OTN muestra que el perfil de usuarios de estas terapias son personas de clase media alta y alta, entre 36 y 45 años, residentes en áreas metropolitanas y mayor porcentaje de mujeres que de hombres. El grado de satisfacción tras practicarlas es prácticamente sobresaliente en las terapias más utilizadas según el OTN $^{5}$ y alrededor de 7 puntos sobre 10 en el caso de la homeopatía y la acupuntura según datos del CIS ${ }^{6}$.

Este mismo estudio contiene un análisis cualitativo de la situación de la MTC. En relación a la imagen que la sociedad percibe de este tipo de terapias, los usuarios

\footnotetext{
${ }^{4}$ El estudio se realizó entrevistando a una muestra de 2000 individuos entre 16 y 65 años con un error muestral de +/- 2, 25\% y un nivel de confianza del 95\%.

${ }^{5}$ Con una media de 4,18 sobre 5 .

${ }^{6}$ Todas las terapias analizadas tienen una puntuación de 7 a 10 en una escala de satisfacción creciente del 1 al 10.
} 
Moreno Tarín, S. (2019).

Estudio sobre el uso de la evidencia científica como argumento en los relatos periodísticos sobre terapias complementarias en los principales diarios digitales

pp. 122/152

remarcan como aspecto positivo que se trata al ser humano desde un punto de vista holístico y le atribuyen eficacia, confianza, prestigio y seriedad ${ }^{7}$. Sin embargo, como aspectos negativos se destaca la falta de conocimiento, informaciones incompletas y a veces confusas, así como desconfianza de técnicas y de profesionales, a los cuales se les exige capacidad para escuchar, saber expresarse y orientar. Los motivos principales por los que la población no usa este tipo de terapias son la falta de interés o necesidad y la percepción de que la medicina convencional es suficiente, según los datos del CIS. En términos generales, la demanda pública en cuestión de salud es, por tanto, la exigencia de una información fiable, una regularización de la MTC y una atención y confianza mayor por parte del personal médico.

La desconfianza de la medicina convencional no parece dar explicación al aumento del uso de la $\mathrm{MTC}^{8}$, puesto que la mayoría de los usuarios que recurre a ella no lo suele hacer de forma alternativa, sino complementaria. No obstante, sólo un $20 \%$ de los usuarios comunica al personal médico convencional la práctica simultánea de éstas. Cabe promoverse una reflexión acerca de en qué condiciones se está trabajando en la sanidad pública y fomentar una relación médico-paciente más satisfactoria que evite problemas de falta de comunicación y confianza (Ballvé Moreno, 2003). Asimismo, para poder llevar a cabo una iniciativa individual del paciente de búsqueda entre la diversidad diagnóstica y terapéutica segura y avalada científicamente, se debe corresponder con un diseño de políticas públicas utilizando la complementariedad de técnicas médicas como un elemento de desarrollo principal (Duarte Gómez, 2003).

En relación con la normativización del sector, el estudio del OTN de 2008 concluye que una regulación oficial de estas técnicas daría seguridad y confianza a los usuarios, hecho que refuerza la idea propuesta por la OMS (2013) de establecer estrategias de inserción de MTC en el Sistema Nacional de Salud. Por el momento, la regulación de técnicas, centros y profesionales para llevar a cabo la MTC en España es muy escasa (Ministerio de Sanidad, 2011).

En España, las terapias pertenecientes a la MTC más utilizadas son: yoga (32,5\%), acupuntura (31,5\%), quiromasaje (28,4\%), homeopatía (23\%), Reflexiología podal $(16,1 \%)$, Tai Chi $(13,3 \%)$, terapia floral $(12 \%)$, drenaje linfático $(9,1 \%)$, naturopatía $(8,8 \%)$, Reiki (8,4\%), Osteopatía (8,2\%), Shitatsu (3,9\%) y kinesología $(2,1 \%)$, según el OTN (2008). Según el CIS (2018) cada una de estas terapias se utiliza en una frecuencia diferente, siendo el Yoga la más utilizada al menos una vez a la semana y situándose la acupuntura, la reflexiología podal, la quiropráctica o la homeopatía lejos de considerarse las más utilizadas con esta periodicidad. Sin

\footnotetext{
${ }^{7}$ El CIS lanzó una serie de preguntas relacionadas con el uso y la percepción de estas terapias, en su barómetro de febrero, que refuerzan los datos del estudio de hace una década, siendo "la cura de enfermedades y dolencias para las que la medicina convencional no funciona”, el segundo motivo principal por el que las personas encuestadas usan este tipo de terapias.

${ }^{8}$ El barómetro del CIS (2018) muestra que un 81,5\% está muy satisfecho o completamente satisfecho con el tratamiento médico recibido por el Sistema Nacional de Salud.
} 
Moreno Tarín, S. (2019).

Estudio sobre el uso de la evidencia científica como argumento en los relatos periodísticos sobre terapias complementarias en los principales diarios digitales

pp. 122/152

embargo, estas cuatro últimas terapias se utilizan mucho más de forma puntual que el Yoga.

\subsection{Medicina Tradicional y Complementaria basada en la evidencia científica}

La Medicina Tradicional y Complementaria basada en la evidencia científica es un concepto aceptado desde finales del siglo XX y principios del siglo XXI (Sungmi Lian, 2010; De Almeida Adrede y Schlechta Portella, 2018). Algunas de las terapias de la MTC han pasado por estudios científicos sistemáticos. El libro The ACP Evidence Based Guide to Complementary and Alternative Medicine de los autores Bradley P. Jacobs y Katherine Gundling, publicado en 2009, es una guía que agrupa información sobre la MTC acompañada de una revisión de la evidencia científica que se conocía hasta el momento acerca de cada terapia. También se puede encontrar online la herramienta virtual Cochrane ( https://www.cochrane.org/es/evidence), una organización internacional sin ánimo de lucro que tiene como objetivo principal ayudar a la toma de decisiones médicas fundamentadas científicamente. En su página web se encuentra disponible una base de datos donde encontrar estudios sobre la evidencia científica de algunas de las terapias pertenecientes a la MTC. Este instrumento de búsqueda es generado por una red global independiente de personal investigador y profesional, así como de pacientes, personas cuidadoras y interesadas en la salud. Se ha visto como el aumento de la utilización de este tipo de terapias ha ido en concomitancia con la demanda de medicamentos basados en la evidencia científica. Esta divergencia no se explica porque hay dos tipos de pacientes, sino porque son los mismos pacientes que utilizan estas terapias los que exigen saber si funcionan y si son seguras (Celia Moss, 2001).

Dentro de la medicina convencional, los ensayos controlados aleatorizados son pruebas científicas en las cuales los sujetos de investigación son seleccionados al azar. Cuando se llevan a cabo de forma rigurosa, son consideradas las pruebas con respuestas más fiables dentro de la evidencia clínica estándar para determinar los efectos reales de una intervención médica (Catherine M. Stoney y Laura Lee Johnson, 2017), puesto que los sujetos se consideran estadísticamente equivalentes. El principal motivo es que disminuyen el sesgo cognitivo, evitando en la medida de lo posible una mala interpretación de los resultados de los estudios. Esta confusión es producida por elementos o factores externos al objetivo del análisis y en otros tipos de pruebas no se pueden discernir, sin embargo, la aleatorización sí es capaz de reducir este efecto (Simon Dagenais y Scott Haldeman, 2012).

Con todo, la MTC, por su naturaleza no reduccionista y los fundamentos en los que se respalda, requiere nuevos métodos de análisis con medidas que atiendan a la multifactoriedad y abrir paso a investigaciones que generen nuevos patrones de evidencia capaces de analizar un sistema más complejo (Verhoef et al., 2005). Esta problemática, que no es exclusiva de la MTC, sino que ocurre con otros tratamientos médicos complejos de la medicina convencional como son los utilizados en curas paliativas o en oncología, ha llevado a la investigación de alternativas metodológicas importantes (De Almeida Adrede y Schlechta Portella, 2017). 
Moreno Tarín, S. (2019).

Estudio sobre el uso de la evidencia científica como argumento en los relatos periodísticos sobre terapias complementarias en los principales diarios digitales

pp. 122/152

Una de estas directrices para el desarrollo de nuevos tipos de evidencia científica que se están planteando es la Investigación de Sistemas Enteros (WSR, del inglés whole systems research) y de métodos $\operatorname{mixtos}^{9}$, mediante los cuales se utilizan enfoques diagnósticos y terapéuticos que tienen en cuenta los cambios globales de los pacientes. Para ello utilizan patrones de estudio de subsistemas de las personas, su interrelación y la evolución de los mismos, contemplando su contexto ambiental. Esta es una perspectiva innovadora frente al modelo de ciencia reduccionista clásico de la biomedicina farmacéutica (Bell y Koithan, 2006) y con él se pretende unificar los dos mundos médicos en una sola nomenclatura y un único sistema de herramientas comunes, sin desvalorizar los ensayos actuales que sí son útiles en determinadas ramas científicas y clínicas.

Este nuevo tipo de perspectiva contempla por ejemplo la relación entre el personal médico y el paciente, así como las expectativas de este último en el proceso clínico, a fin de mejorar el tratamiento terapéutico. Esta preocupación por integrar en los análisis factores que van más allá de las meras limitaciones inherentes a los métodos científicos de análisis tradicionales viene dada por el convencimiento de que muchas de las limitaciones son consecuencia de sistemas sociales, culturales y educativos (De Almeida Adrede y Schlechta Portella, 2017).

Autores como José Luís Ballvé Moreno (2003) sugieren que el auge de la MTC actual invita a reflexionar sobre un modelo clínico donde el personal médico convencional debería ser capaz de valorar y criticar la credibilidad de los tratamientos clínicos y poder emplear más tiempo con los pacientes. Y para ello debe replantearse qué recursos se están destinando al sistema de sanidad pública. El estudio remarca que "el creciente acceso a información sanitaria plantea a los médicos un cambio en la relación asistencial. Los ciudadanos se situarán cada vez más en un plano de igualdad con el profesional". Y que "afortunadamente se ha acabado el papel del médico paternalista, investido de una autoridad incuestionable”.

\subsection{Medicina Tradicional y Complementaria y medios de comunicación}

Gran parte de la información que recibe la ciudadanía acerca de la MTC es confusa, por ser inexacta o incompleta y una de estas carencias es la evidencia científica como argumento periodístico (Billie Bonevski et al., 2008) (Van Dijk, 2010). Esto puede ser debido, por un lado, a la falta de información accesible para los profesionales de la comunicación sobre la eficacia científicamente probada de este tipo de terapias y, por otro lado, a la falta de formación del sector periodístico en el terreno de la ciencia, que deriva en la creación de noticias sensacionalistas en temas de salud y en una desproporcionada atención por parte del público hacia estas.

\footnotetext{
9 “Los métodos mixtos combinan la perspectiva cuantitativa y cualitativa en un mismo estudio, con el objetivo de darle profundidad al análisis cuando las preguntas de investigación son complejas. Más que la suma de resultados cuantitativos y cualitativos, la metodología mixta es una orientación con su cosmovisión, su vocabulario y sus propias técnicas, enraizada en la filosofía pragmática con énfasis en las consecuencias de la acción en las prácticas del mundo real” (Alicia Hamui-Sutton, 2013).
} 
Moreno Tarín, S. (2019).

Estudio sobre el uso de la evidencia científica como argumento en los relatos periodísticos sobre terapias complementarias en los principales diarios digitales pp. 122/152

Según F. Ransohoff y M. Ransohoff, una de las consecuencias de publicar textos periodísticos que tratan temas de salud distorsionados, apoyados en el sensacionalismo, es que pueden crear falsas esperanzas y temores injustificados. Según los autores "después de un comunicado de prensa sensacionalista, tanto periodistas como el personal científico pueden apuntar los dedos de responsabilidad los unos a los otros, a pesar de que ambos pueden beneficiarse de la polémica o la atención de los medios que recibe una historia sensacionalista”. Esto es posible ya que "la responsabilidad de informar distorsionadamente en las páginas de una revista médica recae claramente en los editores y autores, pero, la responsabilidad de un comunicado de prensa es menos clara: un comunicado de prensa existe más allá de las comprobaciones y los saldos que forman parte de la cultura de revisión por pares de una revista”.

El hecho de que las noticias sobre MTC no sean provistas de información científicamente contrastada tiene entre sus consecuencias la falta de recursos de los que dispone la sociedad para tomar decisiones informadas sobre su salud. Esto sucede debido a que los medios de comunicación juegan un papel importante a la hora de introducir opciones de tratamiento médico a personas con diferentes enfermedades como el cáncer (Laura Weeks et al., 2007), aunque estudios realizados en 2015 en España concluyen que no existe una correlación entre la frecuencia de publicaciones en los diarios digitales de noticias sobre MTC y su uso (Moreno Castro y Lopera Pareja, 2016).

Existen instrumentos para que periodistas puedan reconocer si una investigación o una revisión sistemática tiene calidad científica. Una de ellas es el sistema GRADE (Grading of Recommendations Assessment, De-velopment and Evaluation), el cual aporta un marco riguroso y es un recurso utilizado por organizaciones como la OMS o la Colaboración Cochrane (Asociación Española de Comunicación Científica (AECC), 2013).

En relación a cómo se construye discursivamente la MTC en los medios de comunicación, algunos estudios apuntan a que las revistas científicas de impacto como Science, Nature o The New England Journal of Medicine utilizan discursivamente el riesgo que tienen dichas terapias como forma de circunscribir el discurso al grado de aceptación que tienen estas en el sistema convencional de salud (Fernández Branson, 2014). Sin embargo, en los medios de comunicación de masas generalmente se pueden encontrar diferentes tipos de enfoques. Los enfoques positivos, en los que se legitima el uso de la MTC como respuesta a los limites que puede presentar la biomedicina, y los enfoques negativos, en los que se entienden estas prácticas como cuestionables y arriesgadas (Mercurio y Eliott, 2011). 
Moreno Tarín, S. (2019).

Estudio sobre el uso de la evidencia científica como argumento en los relatos periodísticos sobre terapias complementarias en los principales diarios digitales

pp. 122/152

\section{Objetivo del estudio}

Este trabajo tiene como objetivo principal analizar el peso de la evidencia científica, como argumento que se esgrime, o no, en el debate sobre las terapias no convencionales a través de los flujos de información que se difunden en los medios digitales de prensa generalista en España. Para llevar a cabo el análisis se han planteado una serie de preguntas, delimitando así el objeto de estudio:

A. ¿Aparece la evidencia científica como argumento en 5 de los diarios digitales de mayor audiencia en España (El Periódico, El País, El Mundo, La Vanguardia y $A B C$ ), durante los años 2015, 2016 y 2017? ¿Cómo aparece este argumento? ¿Existe alguna tendencia creciente o decreciente entre este periodo de tiempo?

B. ¿Existe alguna relación entre el encuadre de la noticia (favorable o escéptica) y la presencia de la evidencia científica como argumento periodístico?

C. ¿Existe correlación entre el tipo de terapia y la presencia de la evidencia científica, como argumento favorable o desfavorable para su uso?

Responder a estas preguntas es el objetivo esencial de esta investigación. Se pretende conocer si existe una infrarrepresentación del argumento de la evidencia científica en estas noticias o no; comprobar si existe una relación entre la posición del texto (positiva o negativa) y la utilización de esta evidencia como argumento; y determinar esta relación también con las variables "terapia” y "periódico”.

El interés por analizar la prensa digital para este estudio viene dado porque esta forma parte del sistema de medios de comunicación, los cuales eran la principal fuente de información a la que recurría la población para informarse y tomar decisiones sobre las terapias naturales, hace una década (Evans et al., 2007, Molassiotis et al., 2005 y McHughes y Timmermann, 2005). Algunos de estos estudios apuntaban a que el número de noticias acerca de terapias no complementarias estaba relacionado con el aumento de su uso McHughes y Timmermann (2005). Actualmente, los datos anteriormente citados concluyen que los medios convencionales no son la primera fuente de información, sino que en primer lugar está "el boca a boca"; seguido de internet. No obstante, el interés de los diarios digitales deriva de sus implicaciones en la construcción de los temas de interés de la agenda social. Es decir, que cómo los temas sociales, se registran en los medios y estos en la sociedad, siguiendo el modelo teórico de los encuadres noticiosos de Scheufele, \& Tewksbury (2006).

El objeto de estudio es de gran relevancia porque a priori no podemos asumir que en la esfera mediática se baraje la evidencia científica como argumento, tal y como han manifestado en sus trabajos diferentes autores como Teun Van Dijk (2010) ${ }^{10}$. Además, el uso de terapias alternativas a la medicina convencional es un fenómeno que suscita interés en la opinión pública, llegando a ser un tema controvertido social y políticamente (Cano Orón y Moreno Castro, 2017).

${ }^{10}$ Uno de los fundadores del Análisis crítico del discurso, un enfoque interdisciplinar en el estudio del discurso. 
Moreno Tarín, S. (2019).

Estudio sobre el uso de la evidencia científica como argumento en los relatos periodísticos sobre terapias complementarias en los principales diarios digitales

pp. 122/152

\section{Metodología}

La técnica de registro de datos utilizada en el estudio es el análisis de contenido estándar. Se trata de un conjunto de procedimientos interpretativos de productos comunicativos que tienen por objeto elaborar y procesar datos relevantes sobre las condiciones en que se han producido aquellos textos, o sobre las condiciones que puedan darse para su empleo (Klaus Kripendoff, 1989). Así, el análisis de contenido de un texto permite no solo dilucidar el significado del propio texto, sino conocer indicios sobre el modo de producción del mismo que nos dan información sobre el emisor. Wimmer y Dominick (1996) asignan tres características al análisis de contenido: sistematicidad (la selección de contenidos en categorías se realiza en base a unos criterios estandarizados), independencia del autor o autora de los textos y ser cuantitativo.

Es una práctica de investigación muy consolidada en ciencias sociales que consiste en seleccionar un objeto de estudio (noticias, en este trabajo) y analizar productos comunicativos que objetivamente pertenecen a estos textos. Estos productos comunicativos son significativos para conocerla desde una perspectiva teórica, y son válidos para poner a prueba las condiciones en virtud de las cuales estos productos comunicativos han sido empleados. (Piñuel Raigada, 2002).

Para llevar a cabo el análisis de contenido se han seguido las siguientes pautas:

\subsection{Pre-análisis}

Las noticias objeto de análisis han sido facilitadas por el grupo de investigación ScienceFlows en el que participan investigadores provenientes de la Universitat de València, del Centro de Investigaciones Energéticas, Medioambientales y Tecnológicas (CIEMAT), de ESIC Business\&MarketingSchool de València, de la Universidad Europea de València y de la Florida Universitaria. Las noticias fueron buscadas sistemáticamente por parte del equipo de investigación ScienceFlows en la base de datos MyNews (http://uv.mynews.es/hu/). Del volumen total de noticias encontradas, se han seleccionado exclusivamente aquellas cuya posición era favorable o escéptica, descartando las que presentaban un encuadre neutro o equidistante.

Nos referimos a que una noticia tiene un enfoque favorable cuando la forma de narrar los hechos noticiosos implica esquemas de percepción positivos para la audiencia. Así, las consecuencias que derivan de la lectura de la noticia es la valoración positiva por parte de la persona lectora acerca del uso de las terapias no convencionales. Por el contrario, una orientación escéptica del texto comunicativo es la selección y exposición de la información por parte de periodistas de forma que se propone una valoración negativa del uso de la medicina complementaria, por establecer una causalidad entre su uso y la aparición de problemas de salud, sociales, económicos o políticos. Por último, llamamos encuadre neutro a aquellas noticias cuya información no sugiere una correspondencia entre el uso de la MTC y hechos valorables exclusivamente positivos o 
Moreno Tarín, S. (2019).

Estudio sobre el uso de la evidencia científica como argumento en los relatos periodísticos sobre terapias complementarias en los principales diarios digitales pp. 122/152

negativos. De forma que, en términos globales, no se puede percibir una intención subyacente del texto hacia la legitimación o hacia el descrédito del uso de estas técnicas.

Los textos analizados son los protagonizados por las siguientes terapias (definiciones del Ministerio de Sanidad, Política Social e Igualdad, 2011):

\section{Homeopatía}

Es un sistema médico integral que se originó en Europa, con un enfoque holístico de la curación. La homeopatía y la medicina homeopática utilizan un enfoque alternativo de la medicina occidental basándose en el principio de similitud y la premisa de "lo semejante cura lo semejante", el estímulo de las propias defensas naturales y la capacidad de curación del cuerpo humano. El tratamiento homeopático comprende la administración individualizada de dosis extremadamente pequeñas de las mismas sustancias que producen un determinado síntoma, utilizadas a dosis muy diluidas, para aliviar dicho síntoma. Esta nueva aproximación fue propuesta a finales del siglo XVIII por Samuel Hahnemann. Aunque se han formulado varias teorías para explicar los posibles mecanismos de acción de la homeopatía, ninguna ha sido científicamente verificada. En muchos países occidentales, entre ellos España, la autorización, registro y dispensación de los medicamentos homeopáticos están regulados por normas que afectan a los medicamentos de uso humano.

\section{Acupuntura}

Es un procedimiento milenario de curación y forma parte nuclear de la medicina tradicional china. El término acupuntura describe una serie de técnicas que comprenden la estimulación de puntos anatómicos del cuerpo utilizando distintas técnicas. La más usada y estudiada es la introducción de finas agujas metálicas en la piel y su manipulación con las manos, el calor o la estimulación eléctrica. En la concepción del equilibrio y la salud de la medicina tradicional china, el balance entre las fuerzas opuestas del yin y el yang y el mantenimiento del flujo de la energía vital (Qi) a través de los denominados meridianos, puede ser restablecido mediante la acupuntura en

puntos específicos del cuerpo que conectan las redes del flujo de la energía vital. Como técnica se usa en el alivio del dolor, mejora del bienestar, y el tratamiento de patologías agudas, crónicas y degenerativas. La acupuntura contemporánea no se ciñe exclusivamente a las bases filosóficas de la medicina china, sino que implementa conceptos neurofisiológicos.

\section{Quiromasaje}

Es el método que aplica maniobras de forma sistemática a estructuras del cuerpo humano, mediante la aplicación de una fuerza externa con las manos, con el propósito de mejorar el estado general y local del usuario. Dentro de esta técnica encontramos maniobras de exploración, preparación, amasamientos, percusiones y maniobras específicas. 
Moreno Tarín, S. (2019).

Estudio sobre el uso de la evidencia científica como argumento en los relatos periodísticos sobre terapias complementarias en los principales diarios digitales

pp. 122/152

\section{Reflexología podal}

Es la práctica de estimular puntos reflejos localizados en los pies mediante la aplicación de presión con el objetivo de obtener efectos beneficiosos reactivos sobre otros órganos y funciones del cuerpo.

\section{La muestra}

Se han seleccionado estas 4 terapias puesto que, según el informe del OTN (2008) y el barómetro del CIS (2018) se encuentran entre las terapias más conocidas y utilizadas, especialmente la acupuntura y la homeopatía. Respecto a la selección de los periódicos digitales para llevar a cabo el estudio, han sido seleccionados en base a aquellos con mayor número de lectores por día durante el periodo de tiempo analizado (2015-2017). Se ha procedido a la consulta de dicha información mediante la página web de la Asociación para la Investigación de Medios de Comunicación (AIMC). Sin tener en cuenta los periódicos deportivos y autonómicos, el orden decreciente respecto a lectores por día durante 2015, 2016 y 2017 es: El País, El Mundo, La Vanguardia, El Periódico y $A B C$.

\subsection{Análisis de contenido}

Para llevar a cabo el análisis de contenido se ha creado una ficha de registro de datos y con las siguientes variables:

\section{Tabla 1. FICHA DE REGISTRO DE DATOS}

\section{Titular}

\section{Fecha de publicación}

3. Terapia protagonista del texto comunicativo (homeopatía, acupuntura, quiromasaje, reflexología podal y genérica). En la categoría "genérica" se engloban aquellas noticias en las cuales se hace referencia a las terapias no convencionales como un global, sin referirse a ninguna técnica en particular

\section{Enlace que direcciona a la publicación online de la noticia}

5. Periódico en el que está publicado el texto (EI Periódico, La Vanguardia, $A B C$, El Mundo y El país)

6. ¿Menciona la evidencia científica? Con respuesta “Sí/No”

7. ¿Cómo se refiere a la evidencia? Es decir, la forma textual con la que se hace referencia a las pruebas científicas existentes en relación a la terapia en cuestión 
Moreno Tarín, S. (2019).

Estudio sobre el uso de la evidencia científica como argumento en los relatos periodísticos sobre terapias complementarias en los principales diarios digitales

pp. 122/152

8. Posición del texto. Con respuesta “favorable" a aquellas que sus argumentaciones derivan en una legitimación del uso de la terapia y “escéptica” aquellas que establecen una relación entre el uso de la técnica y algún tipo de conflictividad

9. Relación con enfermedades. Se detalla si la noticia relaciona el uso de la terapia con alguna enfermedad, 0 no ${ }^{11}$

10. Matizar si el texto utiliza la técnica complementaria como temática principal o secundaria

\section{Forma de hacer mención de la terapia a lo largo del texto}

El total de noticias favorables o escépticas durante los 3 años que nombran alguna de las 4 terapias fue de 256, de las cuales se han descartado del estudio aquellas que no tenían alguna de las terapias no convencionales como tema principal ${ }^{12}$. Así, el número total de noticias que han sido analizadas utilizando la ficha de registro anterior ha sido 134.

\section{Resultados}

\subsection{Resultados globales del análisis del total de noticias}

4.1.1. Datos obtenidos en relación al análisis desde el punto de vista de los periódicos

La tendencia de publicación de noticias con temática principal acerca de las 4 terapias no convencionales es heterogénea respecto a cada año y va en ascenso, contabilizándose un total de 25 noticias en 2015, 50 en 2016 y 59 en 2017.

\footnotetext{
${ }^{11}$ De los datos obtenidos acerca de el uso periodístico de las enfermedades y su relación con las terapias complementarias no se han extraído resultados ni conclusiones por no ser significativos.

${ }^{12}$ En el número total de noticias (256) se encuentran contabilizadas también las noticias que nombran el drenaje linfático como terapia no convencional. Sin embargo, ninguna de ellas tenía esta terapia como temática principal, sino que únicamente la nombraba, y han sido descartadas del estudio.
} 
Moreno Tarín, S. (2019).

Estudio sobre el uso de la evidencia científica como argumento en los relatos periodísticos sobre terapias complementarias en los principales diarios digitales

pp. 122/152

Figura 1. Total de noticias publicadas en cada mes durante el trienio

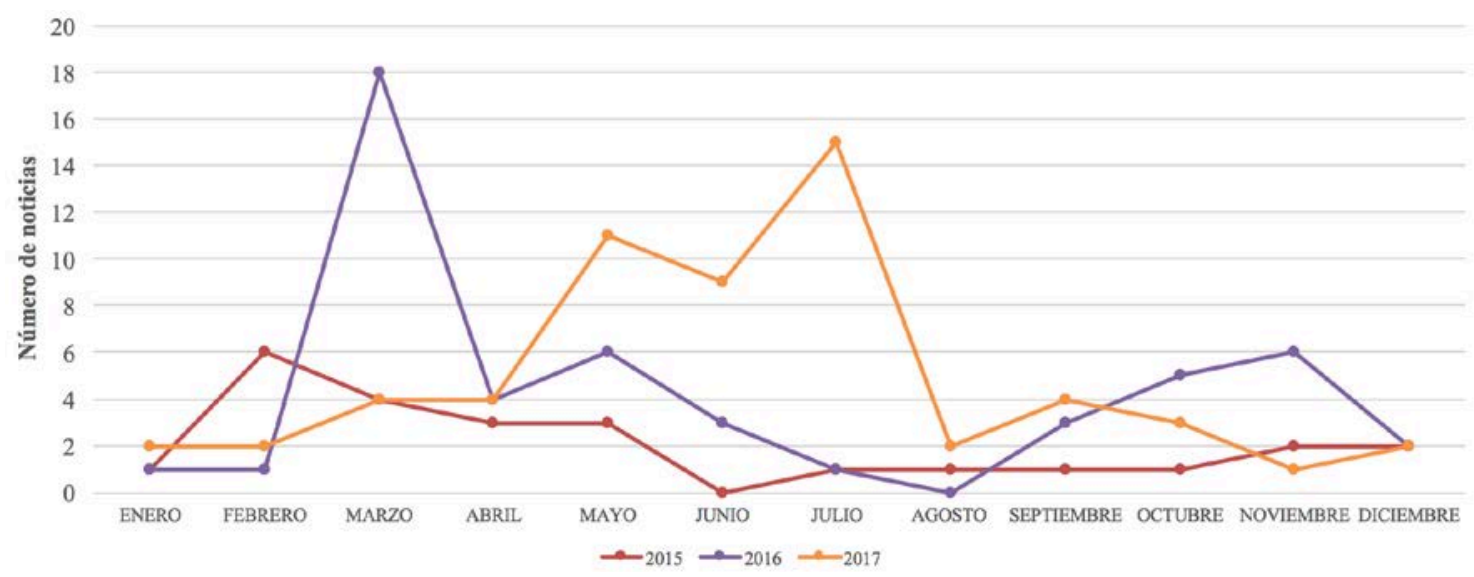

Atendiendo a las noticias publicadas por cada periódico durante el periodo total analizado (figura 2), los porcentajes son, por orden decreciente: El País (37\%), ABC (22\%), La Vanguardia (16\%), El Mundo (12\%) y El Periódico (13\%).

Figura 2. Porcentajes de noticias publicadas por cada periódico durante el trienio estudiado.

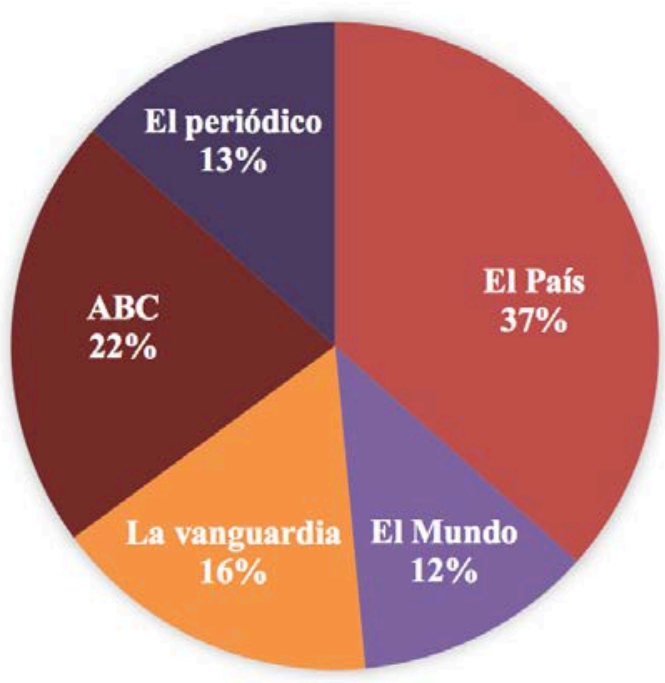

Sin embargo, desglosando estos mismos datos por cada año, se observa como la proporción de noticias difundidas por cada periódico varia significativamente. En 2015 es La Vanguardia el periódico con más noticias publicadas, con un 48\% del total, y se reduce de forma brusca en 2016, pasando a 14\% y finalmente en 2017 representando un $5 \%$ del total de noticias. Ocurre lo contrario con el porcentaje de noticias publicadas por El País, el cual empieza en 2015 con un 24\% del total y sufre 
Moreno Tarín, S. (2019).

Estudio sobre el uso de la evidencia científica como argumento en los relatos periodísticos sobre terapias complementarias en los principales diarios digitales

pp. 122/152

un cambio considerable pasando a 40\% el siguiente año (2016). No obstante, en este caso, se mantiene en un 39\% aproximadamente en 2017.

Se produce un cambio notable de los porcentajes de las noticias publicadas por $E l$ Periódico y ABC. El primero sufre un aumento más accentuado de 2015 a 2016, pasando del $4 \%$ al $14 \%$ y a $17 \%$ en 201 . El $A B C$, por su parte tambien presenta una tendencia al alza entre el 12\% de 2015, el 20\% en 2016 y 27\% en 2017. El Mundo se mantiene en el mismo porcentaje los tres años consecutivos (12\%).

Figura 3. Noticias publicadas por cada periódico

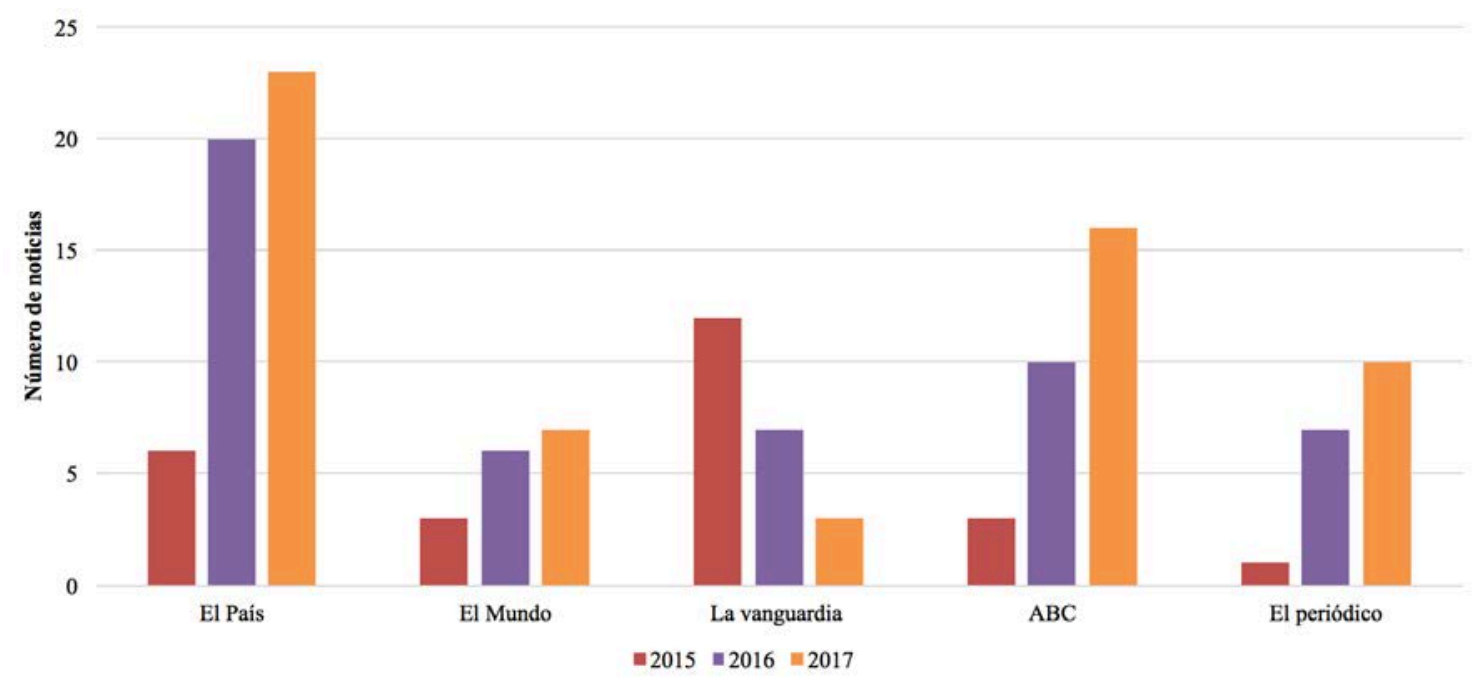

\subsubsection{Datos obtenidos en relación al análisis desde el punto de vista de las terapias}

Del total de 134 noticias estudiadas, existe una clara predominancia temática de la homeopatía frente al resto de terapias. Esta ha protagonizado 104 textos, en segundo lugar, encontramos la acupuntura, la cual ha sido tema principal de los 42 textos. Le siguen las noticias cuya temática es genérica con 34 textos y por último las 7 que hablan de forma principal del quiromasaje y las 2 que tratan la reflexiología podal.

Es importante tener en cuenta que hay algunos textos que están contabilizados de forma doble, por contener en el cuerpo de la noticia información acerca de una terapia, en concreto, pero también encontrar el peso de argumentos en relación con las terapias no convencionales en general. Por lo que la temática de este tipo de noticias está categorizada como el grupo de la terapia analizada, pero también está clasificada como "genérica”. 
Moreno Tarín, S. (2019).

Estudio sobre el uso de la evidencia científica como argumento en los relatos periodísticos sobre terapias complementarias en los principales diarios digitales

pp. 122/152

Figura 4. Número total de noticias publicadas durante los tres años en los 5 diarios en base a la terapia que ocupa la temática principal de la noticia

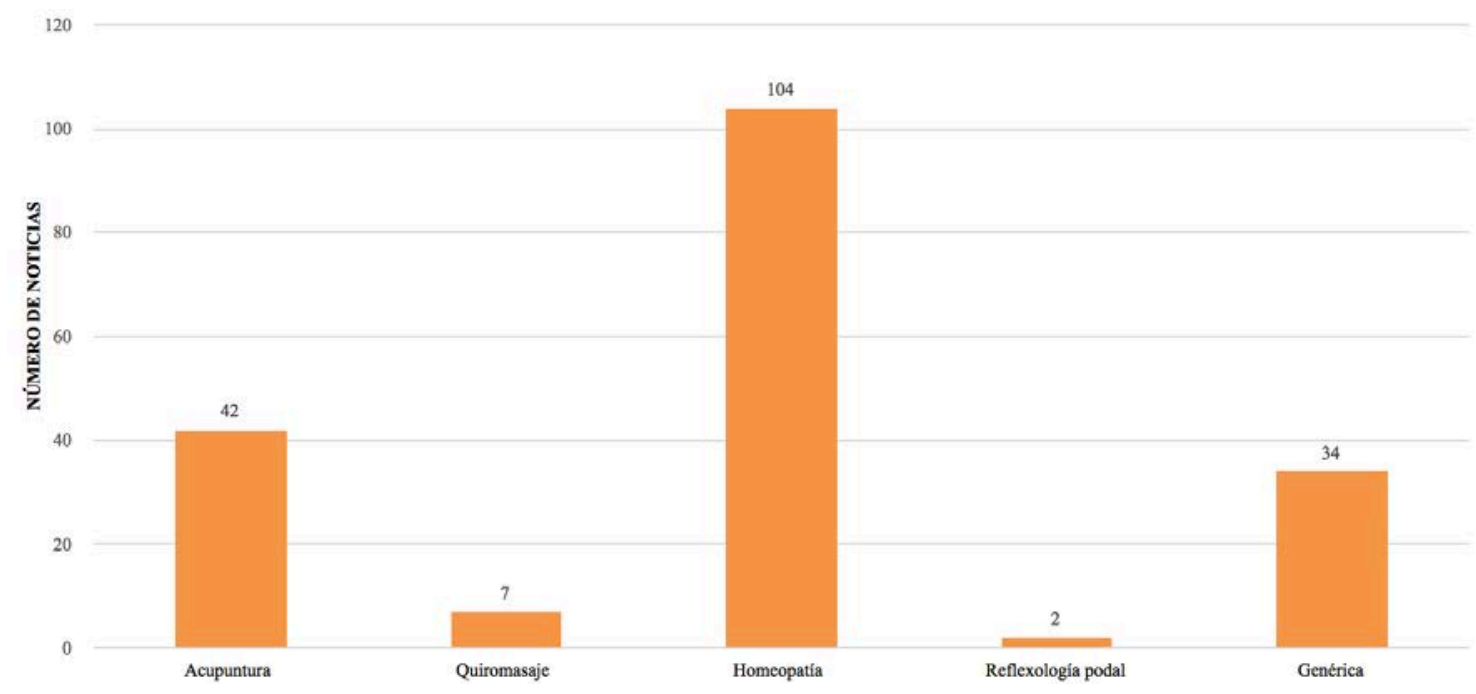

Si analizamos los datos anteriores atendiendo a cada uno de los años por separado, el resultado es una tendencia desigual en función de la terapia analizada. Así:

\section{- Homeopatía}

El número de textos publicados sobre esta temática presenta un fuerte incremento entre los años 2015 (16 noticias) y 2016 (43 noticias). Sin embargo, se mantiene constante entre 2016 (43 noticias) y 2017 (45 noticias). No obstante, al estudiar la relación entre el número de textos publicados con el del resto de terapias en cada uno de los años, encontramos una fluctuación de la proporción de dichos textos. Los textos de homeopatía en el año 2015, suponen un 40\% del total; en el año 2016, un 65\%; y en 2017, un 54\%.

\section{- Acupuntura}

Los textos sobre acupuntura, a pesar de que cuantitativamente se mantienen constante a lo largo de los tres años estudiados (13 noticias, en 2015; otras 13, en 2016; y 16, en 2017), al relativizar los datos en porcentajes por cada año, estos sufren un decrecimiento, pasando de representar un 32\%, en 2015 del total de noticias publicadas, a un $20 \%$, en 2016; y se mantiene constante con un $19 \%$, en 2017.

\section{- Quiromasaje y Reflexiología podal}

Ambas clasificaciones mantienen el número de noticias publicadas constantes durante los tres años (en el caso del quiromasaje), o durante los dos últimos (en el caso de la reflexiología podal). En cuanto a las relativas al quiromasaje el número de noticias publicadas fueron 3, en 2015 (8\% del total); 2, en 2016 (3\%); y 2, en 2017 (3\%). Las noticias sobre reflexología podal, por su lado, no presentaron ningún texto publicado, en 2015; 1, en 2016; y 1, en 2017 (representando un 1\% del total de noticias en ambos años). 
Moreno Tarín, S. (2019).

Estudio sobre el uso de la evidencia científica como argumento en los relatos periodísticos sobre terapias complementarias en los principales diarios digitales

pp. 122/152

\section{- Genérica}

Estas se mantienen constantes entre los años 2015 (8 noticias) y 2016 (7 noticias), pero experimentan un cambio significativo de 2016 (7 noticias) a 2017 (19 noticias). En cuestión porcentual la relación es 20\% en 2015, 11\% en 2016 y 23\% en 2017.

A continuación, se presentan dos figuras ilustrativas de los datos anteriores (figura 4):

Figura 4. Tendencia en la publicación de las noticias atendiendo a las terapias y a cada año

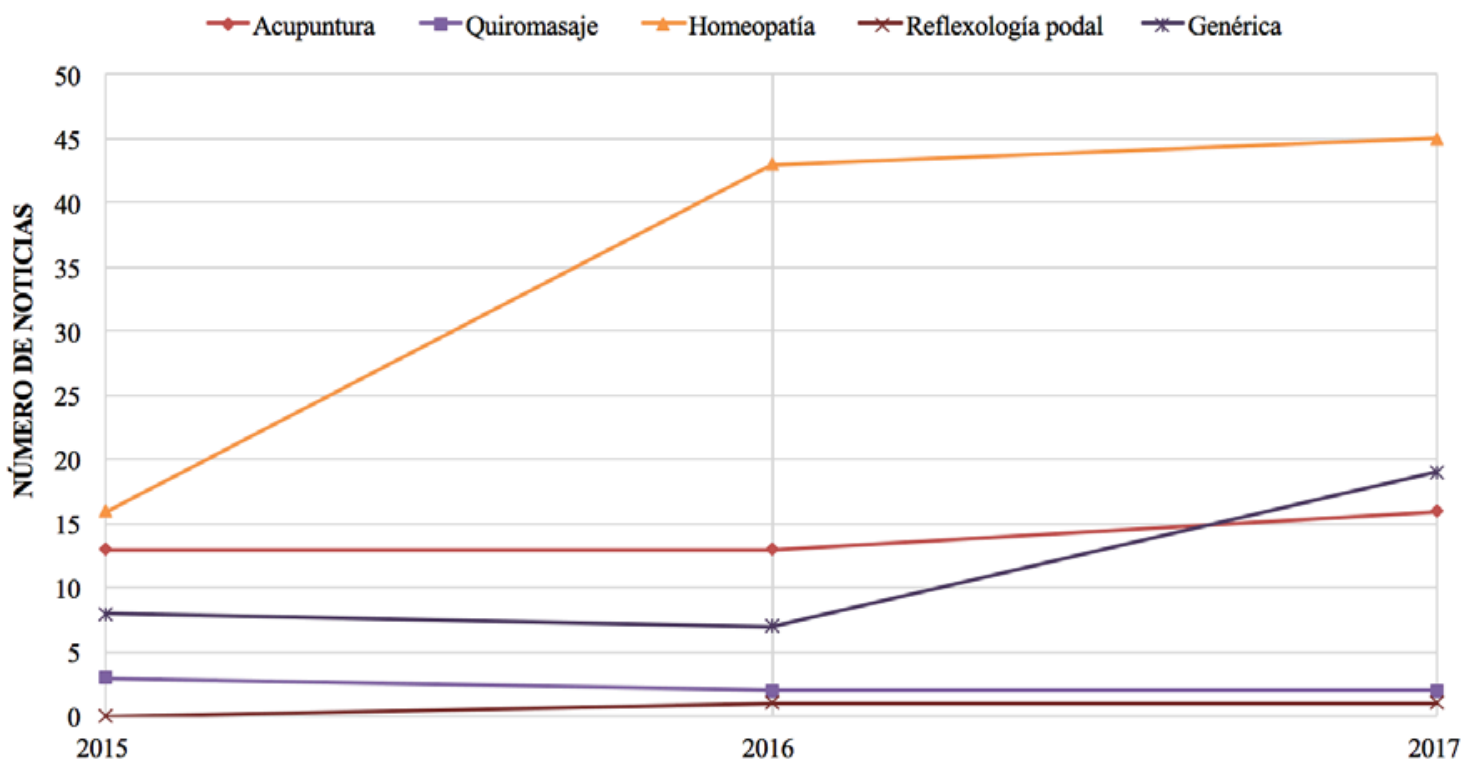

\subsubsection{Datos obtenidos en relación al análisis desde el punto de vista de la posición del texto (favorable/escéptica)}

Si prestamos atención a la posición de los textos apreciamos que en los tres años hay una mayor presencia de textos con enfoque escéptico que con posición favorable. En el análisis total de noticias encontramos 33 favorables, frente a 101 escépticas. 
Moreno Tarín, S. (2019).

Estudio sobre el uso de la evidencia científica como argumento en los relatos periodísticos sobre terapias complementarias en los principales diarios digitales

pp. 122/152

Figura 5. Número de noticias por año representadas en función de la posición del texto

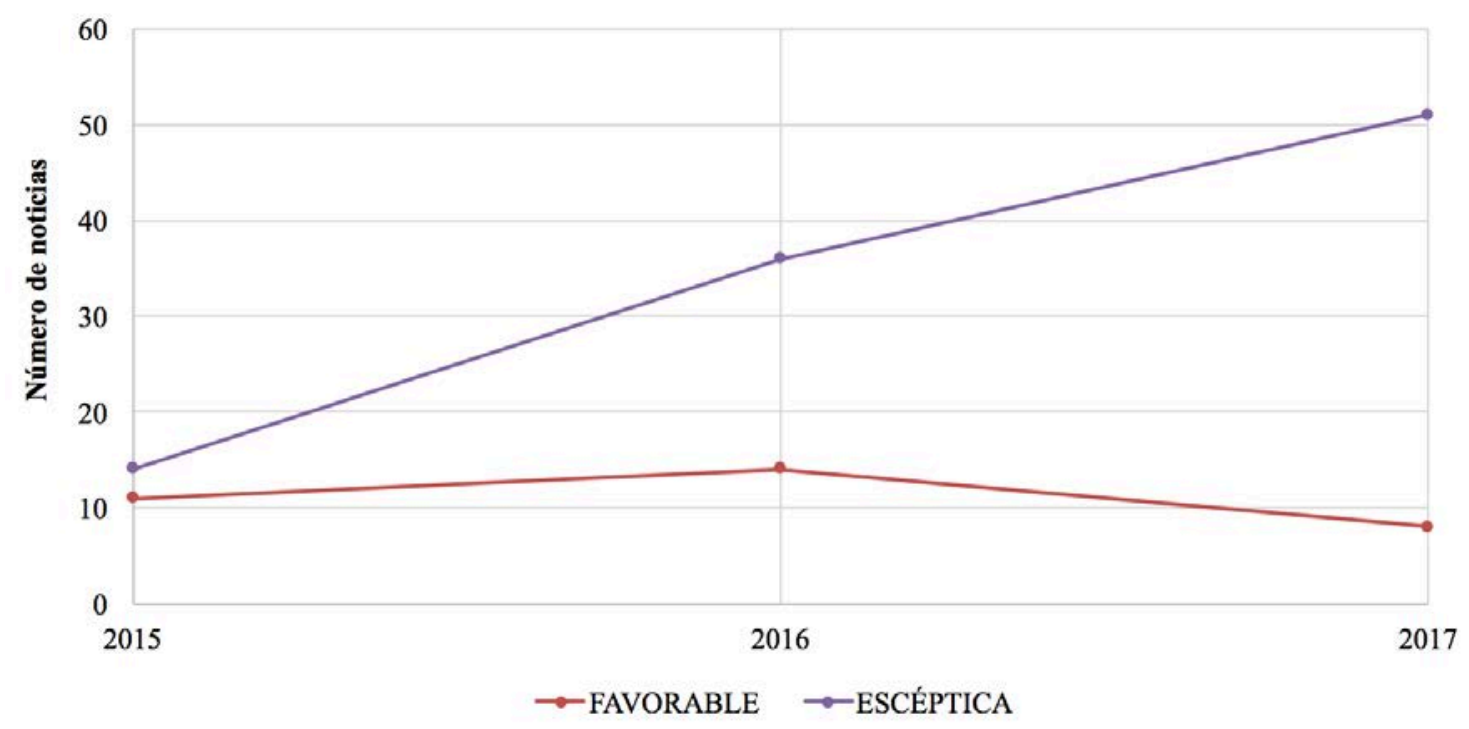

Con estos datos, se puede comprobar que la tendencia de publicación de noticias con argumentos favorables hacia el uso de terapias complementarias y alternativas ha ido decreciendo desde 2015 hasta 2017, mientras que las que presentan un enfoque escéptico tienen una clara tendencia creciente durante estos años. De esta forma, partiendo de un número similar de noticias con enfoque positivo y negativo, la divergencia durante los años es contundente, hasta llegar a 2017 en la que el número de noticias escépticas dista mucho de las favorables.

\subsubsection{Datos obtenidos del análisis de la forma de nombrar a este grupo de terapias en los textos}

Durante el análisis se ha contabilizado el número de veces que se utilizaba cada expresión para referirse a las terapias no convencionales, a fin de poder saber cuales eran las formas más habituales de referirse a estas en la prensa digital española. Los resultados son:

\section{Tabla 2. Formas más recurrentes de nombrar las terapias}

\begin{tabular}{|l|l|l|}
\hline 1 & Pseudociencias & 55 veces \\
\hline 2 & Terapias alternativas & 36 veces \\
\hline 3 & Medicina alternativa & 30 veces \\
\hline & Pseudoterapias & 30 veces \\
\hline 4 & Terapias naturales & 19 veces \\
\hline 5 & Pseudomedicina & 11 veces \\
\hline 6 & Terapias complementarias & 10 veces \\
\hline
\end{tabular}


Moreno Tarín, S. (2019).

Estudio sobre el uso de la evidencia científica como argumento en los relatos periodísticos sobre terapias complementarias en los principales diarios digitales

pp. 122/152

4.2. Resultados globales del análisis de las noticias que mencionan y explican la evidencia científica

\subsubsection{Resultados del análisis de las noticias que mencionan la evidencia científica}

La mayoría de las noticias analizadas nombran la evidencia científica en algún momento del cuerpo del texto, bien como argumentación que refuerza la idea de que existen estudios científicos que avalan el uso de este tipo de terapias o bien para mostrar que no tienen un sustento científico experimental y de efectividad reconocido y probado. En la mayoría de las ocasiones, de las 134 noticias estudiadas, el $77 \%$ recurría a este argumento y el 23\% restante no lo hacía (figura 6).

Figura 6. Porcentaje de noticias en el contenido de las cuales encontramos una mención a la evidencia científica.

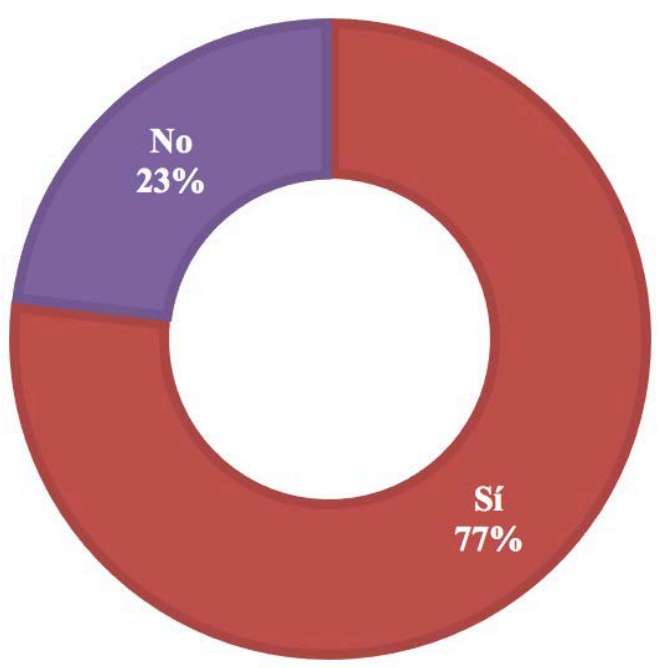


Moreno Tarín, S. (2019).

Estudio sobre el uso de la evidencia científica como argumento en los relatos periodísticos sobre terapias complementarias en los principales diarios digitales

pp. 122/152

Para saber si existe una relación entre la presencia o no de argumentos sobre eficacia científica y la posición del texto se ha aislado cada uno de estos términos y se han relacionado. El resultado es el siguiente:

Figura 7. Proporción de noticias que mencionan la evidencia científica en los textos en relación a la posición de estos

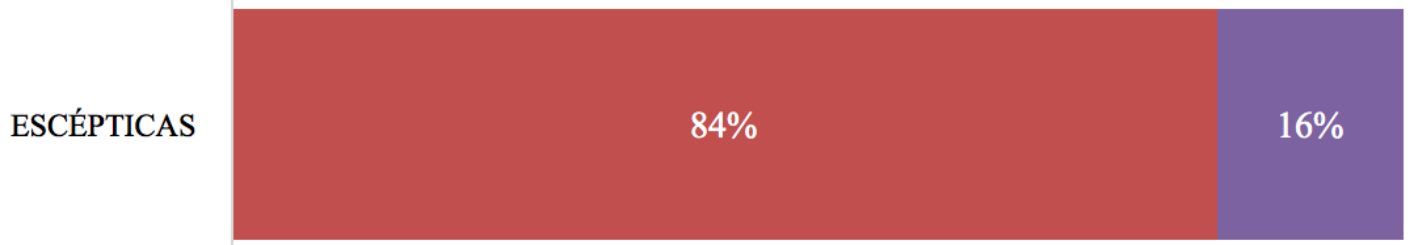

FAVORABLES

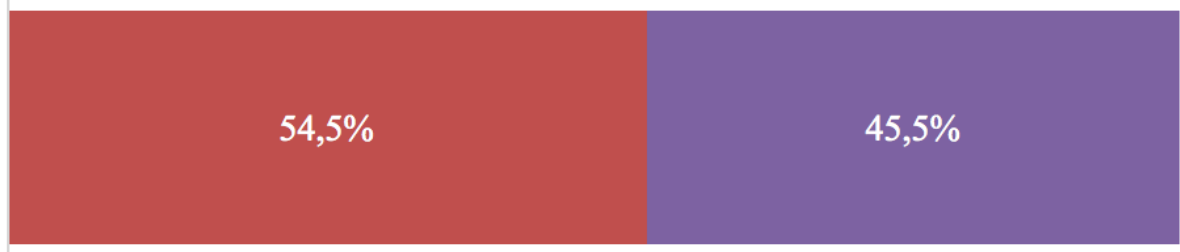

$0 \%$

$20 \%$

$40 \%$

$60 \%$

$80 \%$

$100 \%$

"Sí muestra el argumento $\quad$ No muestra el argumento

Se aprecia con claridad que la utilización de este argumento de evidencia científica y método científico está más presente en las noticias de carácter escéptico, que en las favorables suponiendo un $84 \%$ en las primeras y un $54,50 \%$ en las segundas; una diferencia suficientemente significativa. En la mayoría de los casos, la presencia de dicha argumentación sirve de justificación que respalda la posición favorable o escéptica del texto, de forma que en las noticias escépticas se muestra la falta de estudios científicos que avalen estas terapias o la existencia de investigaciones que concuyen en una ineficacia de estas terapias y en las noticias favorables se utilizan como muestra de que existen estudios que las avalan. Por tanto, la gran mayoría de las noticias con un enfoque escéptico presentan en su contenido la referencia al respaldo de la ciencia convencional. Las noticias con enfoque positivo, utilizan en sus textos este recurso únicament en la mitad de los casos.

Si prestamos atención al número de noticias publicadas que mencionan el respaldo y aval científico de estas terapias (ya sea como legitimación de sus usos o en controversias en su contenido), 16 de las 25 noticias publicadas en 2015, contenían 
Moreno Tarín, S. (2019).

Estudio sobre el uso de la evidencia científica como argumento en los relatos periodísticos sobre terapias complementarias en los principales diarios digitales

pp. 122/152

esta consideración científica; así como 41 de las 50 publicadas en 2016; y 46 de las 59 de 2017. Por tanto, durante los tres años de estudio ha habido una prevalencia mayor de los textos publicados con mención a este aval científico.

Figura 8. Número de noticias en las que se menciona o no el aval científico

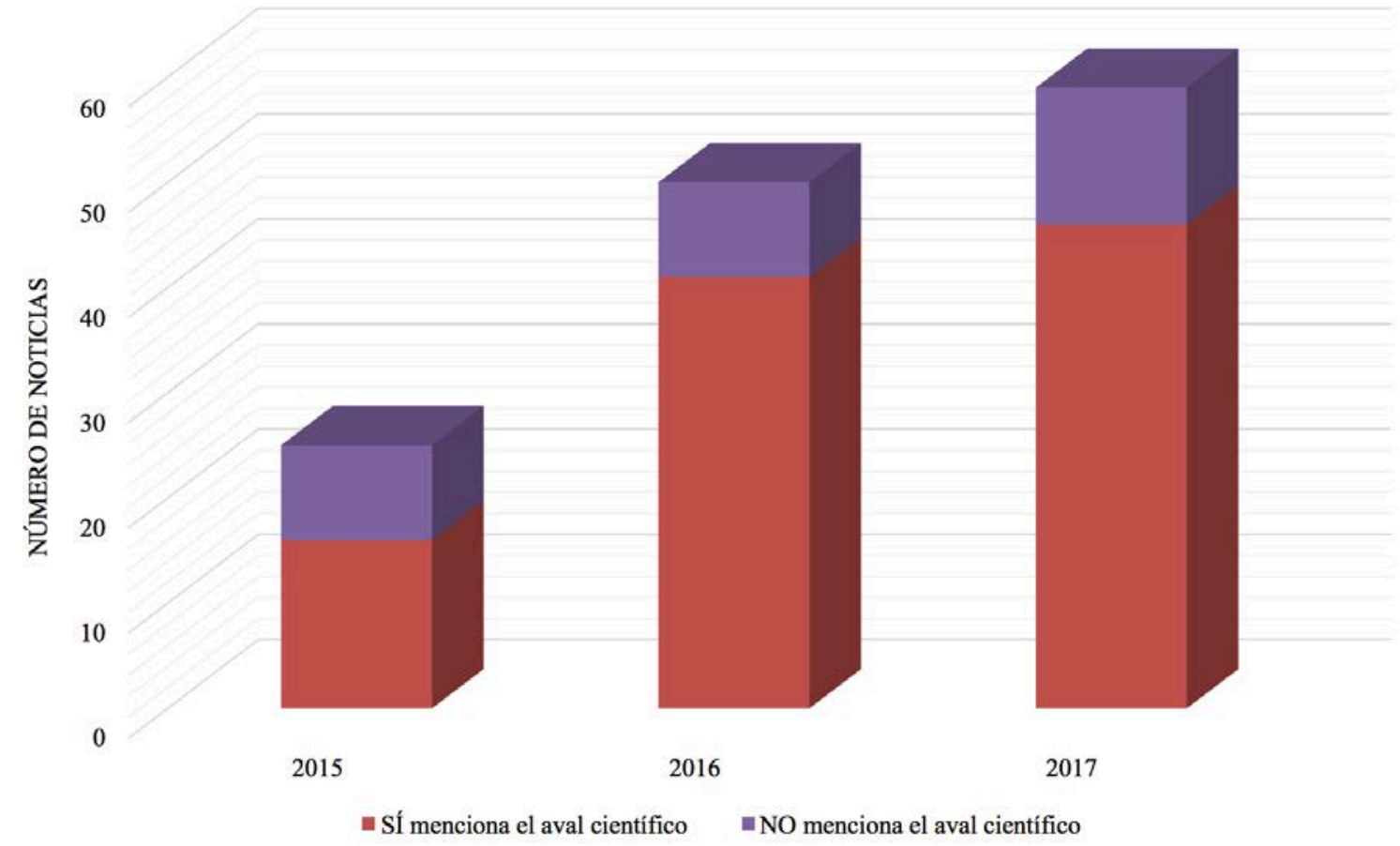

Los resultados de analizar el número de noticias que mencionan la eficacia científica o no en cada uno de los grupos de noticias categorizados, en base a la terapia de la que se hacía alusión en los periódicos son los siguientes:

\section{Tabla 3. resumen del número de noticias que menciona o no la evidencia}

\begin{tabular}{|l|l|l|}
\hline Terapia & $\begin{array}{l}\text { Número de noticias } \\
\text { que menciona la } \\
\text { evidencia }\end{array}$ & $\begin{array}{l}\text { Número de noticias } \\
\text { que no menciona la } \\
\text { evidencia }\end{array}$ \\
\hline Acupuntura & 32 & 10 \\
\hline Quiromasaje & 2 & 5 \\
\hline Homeopatía & 83 & 21 \\
\hline Reflexiología podal & 0 & 2 \\
\hline Genérica & 29 & 5 \\
\hline
\end{tabular}

En relación con los datos, se pueden asumir dos grupos de noticias, por un lado aquellas que en un alto porcentaje mencionan la base científica de las terapias (con un porcentaje mayor al 75\%), y las que no la mencionan en su mayoría (siendo el 
Moreno Tarín, S. (2019).

Estudio sobre el uso de la evidencia científica como argumento en los relatos periodísticos sobre terapias complementarias en los principales diarios digitales

pp. 122/152

porcentaje de mención inferior al 30\%). En el primero de estos dos grupos encontramos aquellas que tratan sobre acupuntura, homeopatía y las que son genéricas. En el grupo restante encontramos las que versan sobre quiromasaje y reflexiología podal.

\subsubsection{Resultados del análisis de las noticias que contienen explicación acerca de la evidencia científica}

De las 103 noticias en las que aparece mención sobre el respaldo científico, ya sea como argumento de legitimación de las terapias o como sustento para otorgar descrédito, 12 de estas desarrollan extendidamente el discurso de la eficacia científica aportando datos y explicaciones. Al relacionar estas 12 noticias con las terapias de las cuales hablan los textos, el enfoque positivo o negativo del texto y los periódicos que las publican, los resultados son los siguientes:

\begin{tabular}{|c|c|c|c|}
\hline $\begin{array}{l}\text { Número } \\
\text { de } \\
\text { registro }\end{array}$ & Posición & Periódico & Terapia \\
\hline 1 & FAV & $\begin{array}{l}\text { La } \\
\text { Vanguardia }\end{array}$ & acupuntura \\
\hline 2 & FAV & $A B C$ & acupuntura \\
\hline 3 & ESC & $\begin{array}{l}\text { La } \\
\text { Vanguardia }\end{array}$ & homeopatía/genérica \\
\hline 4 & ESC & El País & homeopatía \\
\hline 5 & ESC & El País & homeopatía \\
\hline 6 & ESC & El País & homeopatía/acupuntura/genérica \\
\hline 7 & ESC & El País & homeopatía/acupuntura \\
\hline 8 & ESC & El País & homeopatía \\
\hline 9 & FAV & $A B C$ & acupuntura \\
\hline 10 & FAV & $A B C$ & acupuntura \\
\hline 11 & ESC & El País & genérica \\
\hline 12 & ESC & El País & homeopatía/genérica \\
\hline
\end{tabular}

De los 5 medios digitales analizados, solamente tres presentan en sus publicaciones durante 2015, 2016 y 2017 argumentos explicativos de la evidencia científica entre sus noticias. Estos son El País, La Vanguardia y ABC. Y únicamente la homeopatía y la acupuntura son terapias protagonistas de dichas noticias. 
Moreno Tarín, S. (2019).

Estudio sobre el uso de la evidencia científica como argumento en los relatos periodísticos sobre terapias complementarias en los principales diarios digitales

pp. 122/152

\section{Noticias con enfoque favorable:}

En los casos de los textos posicionados a favor del uso de estas terapias es importante señalar que el $100 \%$ de ellos tratan sobre la acupuntura. Además, cabe destacar que 3/4 de estas fueron publicadas por el periódico digital $A B C$, y el cuarto restante es publicado por La Vanguardia.

\section{Noticias con enfoque escéptico:}

En total 7 de las 8 noticias escépticas fueron publicadas por El País; la noticia que resta la publicó La Vanguardia. Así, todas las noticias publicadas por El País presentaron un enfoque escéptico. Es la homeopatía la terapia protagonista de 7 de los 8 textos escépticos, aunque la noticia restante se cataloga como temática genérica, donde se incluye también esta terapia. La acupuntura también comparte protagonismo junto con la homeopatía en dos de estas noticias.

A continuación, se presentan tres gráficos que muestran la relación proporcional existente de las tres variables por separado:

Figura 9. Proporción de noticias en las que se explica la evidencia científica en relación a las terapias

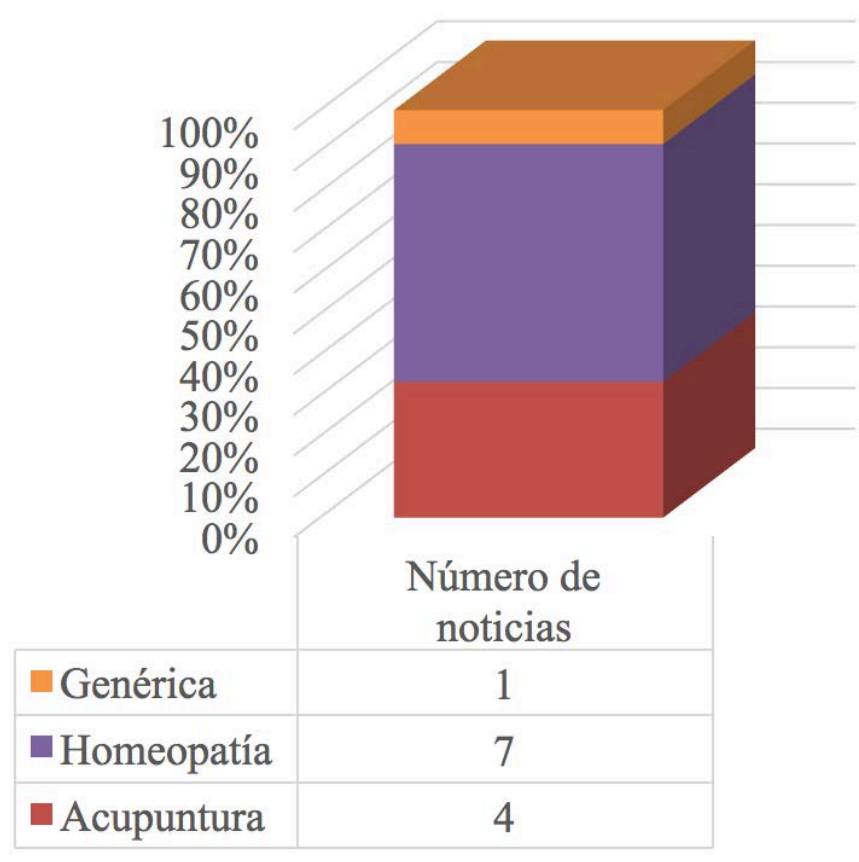


Moreno Tarín, S. (2019).

Estudio sobre el uso de la evidencia científica como argumento en los relatos periodísticos sobre terapias complementarias en los principales diarios digitales pp. 122/152

Figura 10. Proporción y número de noticias en las que se explica la evidencia científica en relación a la posición del texto

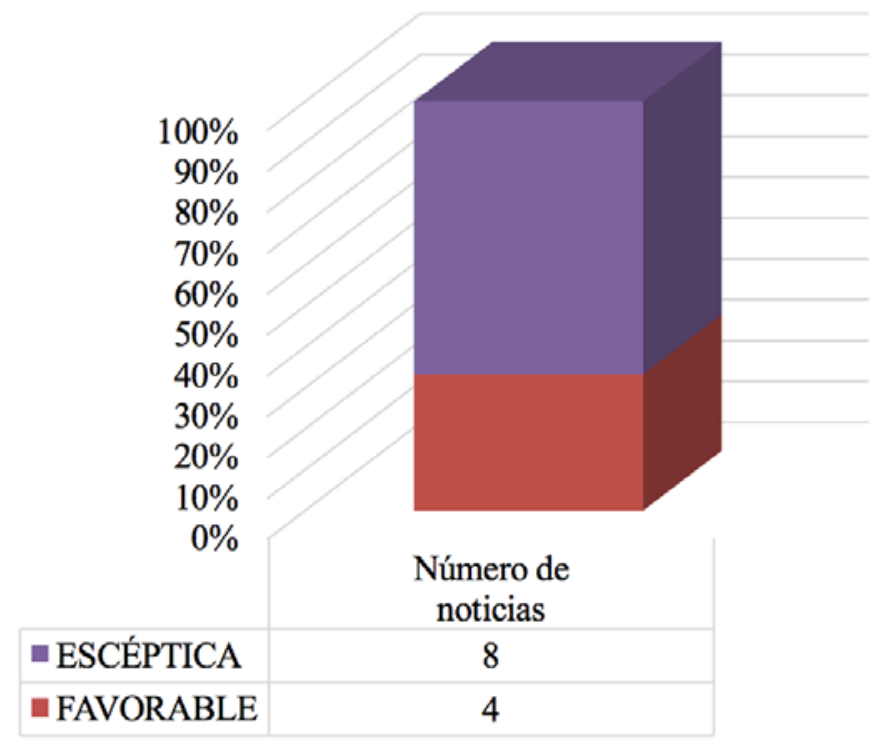

Figura 11. Proporción y número de noticias en las que se explica la evidencia científica en relación a los periódicos

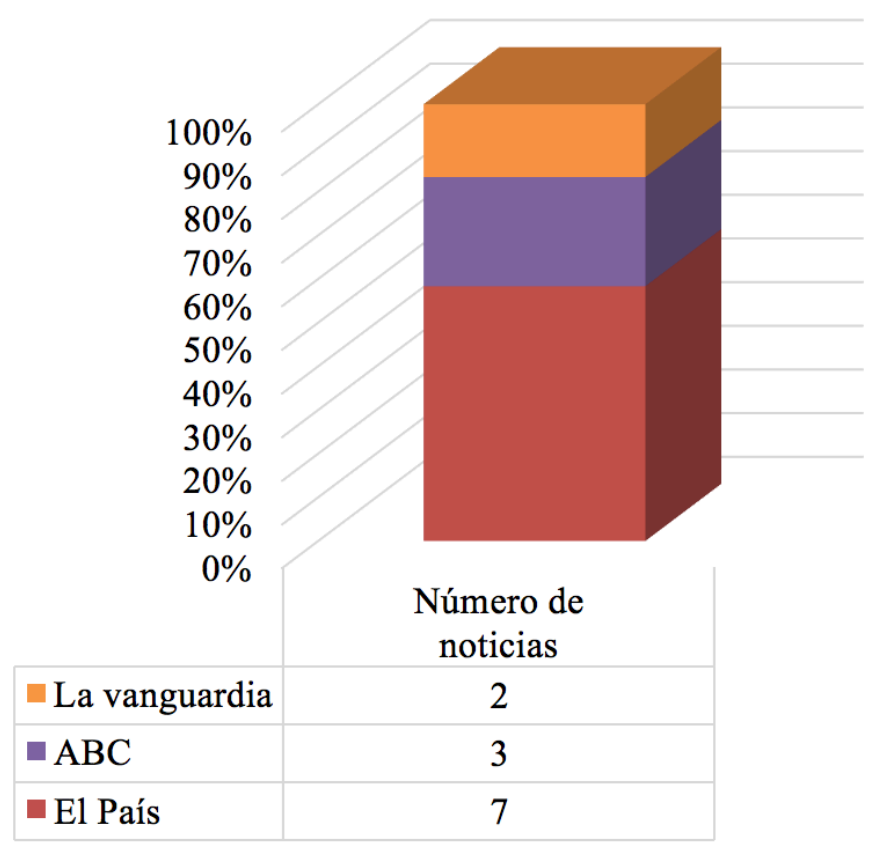


Moreno Tarín, S. (2019).

Estudio sobre el uso de la evidencia científica como argumento en los relatos periodísticos sobre terapias complementarias en los principales diarios digitales

pp. 122/152

En relación con el tipo de argumentaciones que encontramos en estas noticias, podemos clasificarlas de la siguiente manera:

- Explicación de resultados de estudios científicos publicados: noticias 1, 2, 4, 9, 10, 11 y 12.

- Explicación del fundamento científico o psicologico de las creencias "sin fundamento":

noticias 3,7 y 8 .

- Explicación sobre el principio en el que se basa la homeopatía (la base científica de las diluciones, el contexto histórico en el que se desarrolló): noticias 4, 5 y 7.

- Explicación del efecto placebo: noticias 4, 7 y 8 .

- Explicación del método científico o el ensayo clínico: noticias 6 y 8.

De modo que se muestra con claridad que aquellas noticias que presentan un enfoque favorable sobre las terapias no convencionales (noticias 1, 2, 9 y 10) y utilizan en sus noticias argumentaciones desarrolladas sobre la evidencia científica lo hacen detallando resultados de estudios científicos que han trabajado la eficacia de la acupuntura. No osbtante, este mismo argumento también es utilizado en noticias con enfoque escéptico, las cuales, además, contienen los otros tipos de argumentos nombrados anteriormente.

\subsection{Resultados globales}

Con los resultados del presente estudio se puede responder a las preguntas inicialmente planteadas:

A. ¿Aparece la evidencia científica como argumento en 5 de los periódicos de la prensa escrita más leída en España (EI Periódico, El País, EI Mundo, La Vanguardia y ABC) durante los años 2015, 2016 y 2017 ?

Aparece la evidencia científica como argumento en sólo 3 de los primeros 5 periódicos digitales de mayor audiencia en España (sin contar los deportivos y autónomos), durante el trienio comprendido entre enero de 2015 y diciembre de 2017. Estos medios son El País (primer periódico más leído), La Vanguardia ( $3^{\circ}$ más leído) y $A B C$ ( $5^{\circ}$ más leído). 
Moreno Tarín, S. (2019).

Estudio sobre el uso de la evidencia científica como argumento en los relatos periodísticos sobre terapias complementarias en los principales diarios digitales

pp. 122/152

\section{¿Cómo aparece este argumento?}

La evidencia científica aparece en la gran mayoría de los casos únicamente nombrada, haciendo referencia a que esta existe, pero sin ser explicada. Sólo 12 de las 134 noticias analizadas presentan un desarrollo complejo en el texto.

\section{¿Existe alguna tendencia al alza o a la baja entre este periodo de tiempo?}

Ha existido una tendencia en aumento respecto a la publicación de noticias protagonizadas por las terapias no convencionales a lo largo de los años en los cinco diarios analizados.

B. ¿Existe alguna relación entre el encuadre de la noticia (favorable o escéptica) y la presencia de la evidencia científica como argumento periodístico?

La mayoría (84\%) de noticias que presentan un encuadre negativo sobre las terapias no convencionales utilizan en sus argumentos la mención a la eficacia científica. Sin embargo, en las que se posicionan de forma favorable, utilizan este argumento aproximadamente la mitad de los textos (54,5\%).

C. ¿Existe correlación entre el tipo de terapia y la presencia de la evidencia científica como argumento periodístico?

Sí existe una correlación entre el tipo de terapia y este argumento de forma general. Las noticias que tratan sobre homeopatía y acupuntura presentan mención en su contenido acerca de la evidencia científica. También lo contienen las noticias que están relacionadas de forma genérica sobre estas terapias. Mientras que las que se refieren al quiromasaje y a la reflexiología podal no presentan dicho argumento.

\section{Discusión de resultados y conclusiones}

De los resultados obtenidos en el presente estudio, se puede afirmar que durante el trienio estudiado ha habido una evolución temporal creciente de la cobertura mediática sobre terapias no convencionales en la prensa digital de mayor audiencia en España. La mayoría de estas noticias presentaron un encuadre negativo en relación al uso de este tipo de terapias, dato que sugiere exactamente lo contrario a lo que han concluido estudios anteriores, como el realizado por Laura Weeks y Tina Strudsholm, en 2008, en el que se analizó la cobertura en prensa digital y afirmaron que los textos presentaban mayoritariamente un enfoque favorable. No obstante, el claro enfoque negativo de las noticias sobre homeopatía coincide con los resultados de análisis que concluyen que el tratamiento de esta terapia en la prensa española presenta un enfoque de descrédito (Escribà Sales et al., 2015). 
Moreno Tarín, S. (2019).

Estudio sobre el uso de la evidencia científica como argumento en los relatos periodísticos sobre terapias complementarias en los principales diarios digitales

pp. 122/152

Según el barómetro del CIS de febrero de 2018, de las técnicas objeto de estudio en este trabajo, la terapia que se usa con más frecuencia es la homeopatía, seguida de la acupuntura, coincidiendo con la frecuencia de aparición en los medios estudiados. Aunque la concomitancia entre estos dos fenómenos (aparición en medios de comunicación y su uso) parece evidente y hay trabajos que han establecido esta correlación (McHughes y Timmermann, 2005), estudios posteriores afirman que no existe una correspondencia directa entre el interés de la población, la agenda mediática y su uso (Cano-Orón, 2016). Además, parece que la forma principal de informarse y animarse a utilizar estas terapias por parte de la población es "el boca a boca” (Moreno Castro y Lopera Pareja, 2016).

En cuanto a la construcción del discurso de la MTC en la prensa digital española, este trabajo refuerza la idea que plantea Teun Van Dijk: existe una infrarrepresentación de la evidencia científica como argumento periodístico en el área de la medicina tradicional y complementaria. Esto lleva a que, como apuntan Billie Bonevsky, Amanda Wilson y David Henry, la población recibe una información acerca de la MTC deficitaria y confusa. Las escasas noticias en las que aparece una referencia discursiva de la eficacia científicamente probada adoptan una posición generalmente escéptica y con alusiones a estudios clínicos que ponen en cuestión la seguridad de las terapias (la homeopatía principalmente, y la acupuntura en segundo término). Podemos afirmar que los diarios digitales españoles no utilizan herramientas útiles para contrastar la eficacia de las terapias complementarias, como por ejemplo el sistema GRADE ${ }^{13}$ (Grading of Recommendations Assessment, Development and Evaluation) recomendado por la Asociación Española de Comunicación Científica (AECC), para evaluar la confiabilidad y precisión de la información médica.

\section{Bibliografía consultada}

Bell, I. R. y Koithan, M. (2006): "Models for the study of whole systems”, Integrative cancer therapies, vol. 5, no 4, pp. 293-307.

Bonevski, B.; Wilson, A. y Henry, D. A. (2008): “An analysis of news media coverage of complementary and alternative medicine”, PLoS One, vol. 3, no 6, pp. e2406.

Branson, C. (2014): “The discursive construction of complementary and Alternative Medicine (CAM) in women's popular health media and medical journals”. Retrieved from the University of Minnesota Digital Conservancy, http://hdl.handle.net/11299/162632.

\footnotetext{
${ }^{13}$ Hay un estudio, publicado por IZCOVICH et al., en 2016, sobre la información médica de los diarios argentinos utilizando el sistema GRADE de evaluación. Los resultados de este estudio concluyeron que la información médica que difundían los medios de comunicación en Argentina era poco confiable, previendo impactos sobre el funcionamiento del sistema de salud y la relación de los médicos con sus pacientes.
} 
Moreno Tarín, S. (2019).

Estudio sobre el uso de la evidencia científica como argumento en los relatos periodísticos sobre terapias complementarias en los principales diarios digitales

pp. 122/152

Cano-Orón, L. y Moreno-Castro, C. (2017): "Las terapias no convencionales en la campaña de las Elecciones Generales de 2015”, Revista de Comunicación y Salud: RCyS, no 7, pp. 29-47.

Cano-Orón, L. (2016): “Correlación entre las búsquedas sobre terapias complementarias en Google y su uso por parte de la población española”, Panace@: Revista de Medicina, Lenguaje y Traducción, vol. 17, no 44, pp. 124-132.

Cañedo Andalia, R., et al. (2003): "De la medicina popular a la medicina basada en evidencia: estado de la investigación científica en el campo de la medicina tradicional”, Acimed, vol. 11, no 5.

Casino, G. (2013): Bioestadística para periodistas y comunicadores. Barcelona: Fundación Dr. Antonio Esteve.

De Almeida Andrade, F. y Portella, C. F. S. (2017): "Research methods in complementary and alternative medicine: an integrative review", Journal of integrative medicine.

Duarte-Gómez, M. B. (2003): "Medicina occidental y otras alternativas: ¿es posible su complementariedad? Reflexiones conceptuales”, Cuadernos de Salud Pública, vol. 19, pp. 635-643.

Escribà-Sales, E.; Rovira, S. y Alonso-Marcos, F. (2015): "La pseudociencia en los medios de comunicación: estudio de caso del tratamiento de la homeopatía en la prensa española y británica durante el período 2009-2014”, Panace, vol. 16, no 42, pp. 177183.

Evans, M. et al. (2007): "Decisions to use complementary and alternative medicine (CAM) by male cancer patients: information-seeking roles and types of evidence used", BMC Complementary and Alternative Medicine, vol. 7, no 1, pp. 25.

Gómez de la Cámara, A. (2003): "La medicina basada en evidencias científicas: mito o realidad de la variabilidad de la práctica clínica y su repercusión en los resultados en salud”, Anales del Sistema Sanitario de Navarra. Gobierno de Navarra. Departamento de Salud, p. 11-26.

Gutiérrez-Vidrio, S. (2010): “Discurso periodístico: una propuesta analítica”, Comunicación y sociedad, no 14, pp. 169-198.

Hamui-Sutton, A. (2013): "Un acercamiento a los métodos mixtos de investigación en educación médica”, Investigación educ. médica [online]. vol.2, n.8 [citado 2018-08-22], pp.211-216.

Disponible

en:

$<$ http://www.scielo.org.mx/scielo.php?script=sci_arttext\&pid=S2007-

$50572013000400006 \& \operatorname{lng}=\mathrm{es} \& n r m=$ iso $>$. ISSN 2007-5057. 
Moreno Tarín, S. (2019).

Estudio sobre el uso de la evidencia científica como argumento en los relatos periodísticos sobre terapias complementarias en los principales diarios digitales

pp. 122/152

Izcovich, A.; Criniti, J. M.; Popoff, F.; González-Malla, C. y Catalano, H. N. (2016): “¿Cuán confiable es la información médica proporcionada por los medios de comunicación en Argentina?”, Medicina, vol. 76, no 2, pp. 71-75.

Krippendorff, K. (1980): Content analysis. Beverly Hills. California: Sage Publications, vol. 7, p. l-84.

Lian, S. (2011): The ACP Evidence-Based Guide to Complementary and Alternative Medicine. USA, Department of Family Medicine, The University of Texas Medical Branch.

López-Noguero, F. (2002): “El análisis de contenido como método de investigación”, Revista de educación, vol. 4, pp. 167-179.

Matters, P. (2001): "Sensationalism in the Media: When Scientists and Journalists May Be Complicit Collaborators", Effective Clinical Practice, American College of Physicians-American Society of Internal Medicine, vol 4, pp. 185-188.

Mchuges, M. y Timmermann, B. N. (2005): “A review of the use of CAM therapy and the sources of accurate and reliable information. Journal of Managed Care Pharmacy", vol. 11, no 8, pp. 695-703.

Mercurio, R. y Eliott, J. A. (2011): “Trick or treat? Australian newspaper portrayal of complementary and alternative medicine for the treatment of cancer”. Supportive Care in Cancer, vol. 19, no 1, pp. 67-80.

Ministerio de Sanidad (2011): Análisis de situación de las terapias naturales. Madrid: Ministerio de Política Social e Igualdad, España.

Molassiotis, A. et al. (2005): "Use of complementary and alternative medicine in cancer patients: a European survey”, Annals of oncology, vol. 16, no 4, pp. 655-663.

Moreno, J. L. B. (2003): “¿Quién utiliza las medicinas no convencionales y por qué?” Humanitas, Humanidades Médicas, vol. 1, no 2, pp. 31-40.

Moreno-Castro, C. y Lopera-Pareja, E. H. (2016): “Comparative study of the frequency of use of natural therapies among the Spanish population and their public image on digital media”. En 14th International Conference on Public Communication of Science and Technology (PCST), Estambul, Turquía. Retrieved from https://pcst. co/archive/paper/2623.

Moss, C. (2001): The Desktop Guide to Complementary and Alternative Medicine: an Evidence-based Approach. Londres: Edzard Ernst.

Observatorio de las Terapias Naturales (2008): Presentación del primer estudio sobre uso y hábitos de consumo de las terapias naturales en España. Observatorio de las Terapias Naturales, Madrid. 
Moreno Tarín, S. (2019).

Estudio sobre el uso de la evidencia científica como argumento en los relatos periodísticos sobre terapias complementarias en los principales diarios digitales

pp. 122/152

Raigada, J. L. P. (2002): "Epistemología, metodología y técnicas del análisis de contenido”, Estudios de sociolingüística, vol. 3, no 1, pp. 1-42.

Rojas-Ochoa, F. et al. (2013): "El debate sobre la Medicina Natural y Tradicional y sus implicaciones para la salud pública”, Revista Cubana de salud pública, vol. 39, pp. 107123.

Scheufele, D. A. y Tewksbury, D. (2006): "Framing, agenda setting, and priming: The evolution of three media effects models”, Journal of communication, vol. 57, no 1, pp. 9-20.

Stub, T. et al. (2017): "Complementary and conventional providers in cancer care: experience of communication with patients and steps to improve communication with other providers”, BMC complementary and alternative medicine, vol. 17, no 1, pp. 301.

Van Dijk, T. A. (2000): El discurso como interacción en la sociedad: estudios del discurso. Barcelona: Gedisa, pp. 19-66.

Vicente-Mariño, M. (2009): Desde el análisis de contenido hacia el análisis del discurso. La necesidad de una apuesta decidida por la triangulación metodológica. España.

Weeks, L. y Strudsholm, T. (2008): “A scoping review of research on complementary and alternative medicine (CAM) and the mass media: looking back, moving forward”, BMC complementary and alternative medicine, vol. 8, no 1, pp. 43.

Weeks, L.; Verhoef, M. y Scott, C. (2007): "Presenting the alternative: cancer and complementary and alternative medicine in the Canadian print media” Supportive Care in Cancer, vol. 15, no 8, pp. 931-938.

Wimmer, R. D.: Dader, J. Y Dominick, J. R. (1996): La investigación científica de los medios de comunicación: una introducción a sus métodos. España: Bosch.

World Health Organization (2013). Estrategia de la OMS sobre medicina tradicional 2014-2023. World Health Organization: Genebra.

World Health Organization (2002): Pautas generales para las metodologías de investigación y evaluación de la medicina tradicional. Organización Mundial de la Salud, Ginebra. 
Moreno Tarín, S. (2019).

Estudio sobre el uso de la evidencia científica como argumento en los relatos periodísticos sobre terapias complementarias en los principales diarios digitales pp. 122/152

\section{Webgrafía consultada}

- www.cambrella.eu

- http://www.who.int/es/home

- http://www.cis.es/cis/opencms/ES/index.html

- https://www.cochrane.org/es/evidence

- https://www.sciencedirect.com/topics/medicine-and-dentistry/randomizedcontrolled-trial

- https:/www.aimc.es/egm/datos-egm-resumen-general/

- http:// www.guiasalud.es/web/guest/gpc-sns

- www.scienceflows.com 